\title{
Expression and Secretion of Cyan Fluorescent Protein (CFP) in B. subtilis using the Chitinase Promoter from Bacillus pumilus SG2
}

\author{
Abbas Shali ${ }^{1}$, Garshasb Rigi ${ }^{2}$, Majid Pornour ${ }^{3}$ and Gholamreza Ahmadian ${ }^{* 1}$ \\ ${ }^{1}$ Department of Industrial and Environmental Biotechnology, National Institute of Genetic Engineering and \\ Biotechnology (NIGEB) , P.O. Box 14155-6343, Tehran, Iran; ${ }^{2}$ Department of Biology, Faculty of Science, Behbahan \\ Khatam Alanbia University of Technology, Behbahan, Khuzestan, Iran; ${ }^{3}$ Medical Laser Research Center, Academic Center \\ for Education, Culture and Research (ACECR), Tehran, Iran
}

Received 27 July 2016; revised 14 September 2016; accepted 28 September 2016

\begin{abstract}
Background: Improved cyan fluorescent protein (ICFP) is a monochromic, green fluorescent protein (GFP) derivative produced by Aequorea macrodactyla in a process similar to GFP. This protein has strong absorption spectra at wavelengths $426-446 \mathrm{~nm}$. ICFP can be used in cell, organelle or intracellular protein labeling, investigating the protein-protein interactions as well as assessing the promoter activities. Methods: In our previous study, the promoters of two chitinases (ChiS and ChiL) from Bacillus pumilus SG2 were assessed in $B$. subtilis and their regulatory elements were characterized. In the present study, icfp was cloned downstream of several truncated promoters obtained in the former study, and ICFP expression was evaluated in B. subtilis. Results: Extracellular expression and secretion of ICFP were analyzed under the control of different truncated versions of ChiSL promoters grown on different media. Results from SDS-PAGE and fluorimetric analyses showed that there were different expression rates of CFP; however, the UPChi-ICFP3 construct exhibited a higher level of expression and secretion in the culture medium. Conclusion: Our presented results revealed that inserting this truncated form of Chi promoter upstream of the ICFP, as a reporter gene, in B. subtilis led to an approximately ten fold increase in ICFP expression. DOI: 10.18869/acadpub.ibj.21.4.240
\end{abstract}

Keywords: Cyan fluorescent protein, Medical reporter gene, Medical screenable marker, Medicinal protein engineering

Corresponding Author: Gholamreza Ahmadian

National Institute of Genetic Engineering and Biotechnology, Department of Industrial and Environmental Biotechnology, Tehran, Iran;

E-mail: ahmadian@nigeb.ac.ir

\section{INTRODUCTION}

$\mathrm{O}$ ver the past two decades, remarkable progress has been made in the field of viral and nonviral gene transfer systems. It is well known that the measurements of in vivo gene expression at different time intervals and gene localization play essential roles in this process ${ }^{[1-3]}$. The employment of an efficient promoter is one of the most important factors for successful gene expression because of its vital effects on gene transcription both quantitatively and qualitatively.
Numerous promoters have already been isolated from the genomes of different organisms, and great attempts have been made to identify the effects of promoter molecular structures on controlling the gene transcription process. As a consequence, some promoters with well-known structures have been identified, which represented a great potential for gene expression, particularly in plant and animal cells ${ }^{[4]}$. Such promoters are able to control gene transcription and expression in transgenic plants, as well as are able to make improvements in some agricultural features of crops. For instance, the $35 \mathrm{~S}$ promoter of cauliflower 
mosaic virus is the most common promoter used for dicotyledonous transgenic plants ${ }^{[4]}$. It is welldocumented that a promoter with the ability to continuously and permanently express a gene of interest plays an important role in engineering plant or animal cells for either gene therapy purposes or increased resistance against pathogens ${ }^{[5]}$. Furthermore, these promoters are necessary for the expression of reporter genes in transgenic studies ${ }^{[6]}$. In our previous studies, a salt-tolerant bacterium was isolated from soil of some regions in Iran. Such bacteria indicated to be able to express both ChiS and ChiL chitinases under the control of a strong promoter ${ }^{[7,8]}$. The activity of this promoter was evaluated in B. subtilis as a host organism. The full-length ChiS promoter has been shown to have a limited function in protein expression; However, deletion of direct repeats or catabolite responsive elements (CRE) in the promoter leads to its increased activity ${ }^{[9,10]}$. Additionally, improved cyan fluorescent protein (ICFP) is a monochromic, green fluorescent protein (GFP) derivative produced by Aequorea macrodactyla in a process similar to that of GFP $^{[11-15]}$. This fluorescent protein exhibits acceptable absorption spectra at wavelengths of 426 to $446 \mathrm{~nm}$ and can be used for labeling purposes ${ }^{[16]}$.

The aim of this study was to quantitatively evaluate the strength of the chitinase promoters created in the previous studies. In this light, the ICFP reporter gene was inserted into the downstream of the signal sequence, as well as the full-length and truncated forms of the ChiSL promoter. Furthermore, the ability of promoter to drive the protein expression was determined using fluorometry analysis.

\section{MATERIALS AND METHODS}

\section{Bacterial strains, plasmids, media, and growth conditions}

Table 1 represents bacterial strains and plasmids used in this study. Bacillus Spizizen Salts (BSS) minimal media were used in the presence of glucose or chitin.

\section{Bioinformatic analysis of promoters}

All the members of the chitinase protein family were retrieved from the UniProt database in order to find different truncated forms of the chitinase promoter in Bacillus species ${ }^{[17]}$. The NCBI database was used to scan the interested chitinase promoters of nine different species from the Bacillus genus. The promoters were aligned in BioEdit v7.0.1 ${ }^{[18]}$ using ClustalW Multiple Alignment $^{[19]}$. The same procedure of multiple alignment analysis was carried out through MEGA5 $5^{[20]}$ matrix to define the ancestral pattern. Subsequently, the phylogenetic tree was constructed using a bootstrap circulation of 1000 to define the degree of homology between the selected strains.

\section{Recombinant DNA techniques and oligonucleotides}

DNA purification, restriction digestion, ligation, and agarose gel electrophoresis, as well as $E$. coli transformation were performed as described by Green and Sambrook and Russell ${ }^{[21]}$. Enzymes were obtained from Roche (Mannheim, Germany). B. subtilis was transformed based on the standard method described by Leskela et al. ${ }^{[22]}$. Table 1 summarizes the oligonucleotides used in this study.

\section{Plasmids}

All plasmids used in this study were constructed using overlapping PCR. PCR was carried out to construct the plasmid pUP-ChiCFP using primers ChiSLF10 and Up-ChiCFP2, and the plasmid pUPChi2 as a template $(\sim 740 \mathrm{bp})$. Additional PCR was performed using primers Up-ChiCFP1 and CFPR5, and ICFP-Chi as a template $(\sim 780 \mathrm{bp})$. Afterwards the two PCR products were combined in an equal volume, followed by overlapping PCR using primers ChiSLF10 and CFPR5 ( 1500 bp). To construct pUPChi-CFP2, the primary PCR (PCR1) was performed with the primers ChiSLF11 and pUp-ChiCFP2, using pUPChi-2 as a template $(\sim 725 \mathrm{bp})$ and the secondary PCR (PCR2) with the primers CFPR5 and pUP-CRE1 using pUPChi2 as a template $(\sim 780 \mathrm{bp})$. The two PCR products were then combined in equal volumes, followed by overlapping PCR using primers ChiSLF11 and CFPR5 ( 1500 bp). PCR amplicons were cloned into the shuttle vector pDHAFB between the HindIII and SphI restriction sites. To build pUPChi-CFP3 (lacking CRE box+sigma binding site), PCR1 was performed with the primers ChiSLF10 and UP-sig2 and PCR2 with primers ChiSR1J and UP-sig1, both using pUPChi $\Delta$ cre $^{[9]}$ as a template $(\sim 700$ and $\sim 780 \mathrm{bp}$, respectively). These two PCR products were combined in equal volumes, and overlapping PCR was carried out using primers ChiSLF10 and ChiSR1J ( 1480 bp). PCR products were cloned into the pDHAFB vector between the $C f r 9 \mathrm{I}$ and $S p h \mathrm{I}$ restriction sites. All constructs were transformed into $E$. coli Top10 cells, and the positive transformants were selected on LuriaBertani medium containing ampicillin. Subsequently, the colonies containing recombinant plasmids were transformed into $B$. subtilis trpaC2, and selected on Luria-Bertani medium containing kanamycin (10 $\mu \mathrm{g} / \mathrm{ml}$ ) after an incubation at $37^{\circ} \mathrm{C}$ overnight. 
Table 1. Primers, plasmids and strains used in this study

\begin{tabular}{|c|c|c|c|}
\hline Name & Sequence $\left(5^{\prime} \rightarrow 3^{\prime}\right)$ & \multicolumn{2}{|c|}{ Reference } \\
\hline \multicolumn{4}{|l|}{ Primers } \\
\hline UpchiCFP-1 & AATGGGGAAAGTGCAAAAGCCGCGGATTCAATAGAAAAGGTAAGC & Thi & study \\
\hline UpchiCFP-2 & GCTTACCTTTTCTATTGAATCCGCGGCTTTTGCACTTTCCCCATT & Thi & study \\
\hline ChiSLF11 & GGGG AAGCTT CGCAGATGT CAT TGAAGT & Thi & study \\
\hline UP-CRE1 & GCATATGAAAACTAGAAATGTTGTTGTCTTCAGTGC & Thi & study \\
\hline UP-CRE2 & GCACTGAAGACAACAACATTTCTAGTTTTCATATGC & Thi & study \\
\hline UP-sig1 & СTCCACTCACATATACGGTTGTTGTTGTCTTCAGTGCC & Thi & study \\
\hline UP-sig2 & GGCACTGAAGACAACAACAACCGTATATGTGAGTGGAG & Thi & study \\
\hline ChiSLF10 & GGGCCCGGGTCATCAAGACGCAGATGTC & & [9] \\
\hline CFPR5 & GGG GCATGCTTACTTGTACAGCTCGTC & & [9] \\
\hline ChiSR1J & GGGGCATGCGAGCCCACTCTCTCTTTA & & [9] \\
\hline \multicolumn{4}{|l|}{ Plasmids } \\
\hline pDHAFB & amyE, chloramphenicol resistance & $\begin{array}{r}\text { Novagen } \\
\text { Ge }\end{array}$ & $\begin{array}{l}\text { Darmstadt, } \\
\text { many }\end{array}$ \\
\hline pUPChi-CFP & PchiS $_{\triangle 394}$-ICFP, chloramphenicol resistance & Thi & study \\
\hline pUPChi-CFP2 & PchiS $_{\Delta \mathrm{cre}}$ - ICFP , chloramphenicol resistance & Thi & study \\
\hline pUPChi-CFP3 & PchiS $_{\triangle \text { cresig }}$ - ICFP, chloramphenicol resistance & Thi & study \\
\hline pUPChi $\Delta$ cre & & & [9] \\
\hline pUPChi $\Delta$ cre-sig & & & [9] \\
\hline \multicolumn{4}{|c|}{ 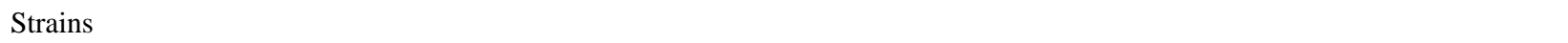 } \\
\hline E. coli Top 10 & $\begin{array}{l}\text { F0 \{lacIq Tn10 (TetR) }\} \text { mcrA D(mrr-hsdRMS-mcrBC) U80lacZDM15 } \\
\text { DlacX74 recA1 araD139 D(ara-leu)7,697 galU galK rpsL endA1 nupG- }\end{array}$ & $\begin{array}{l}\text { Novagen, } \\
\text { Germany }\end{array}$ & Darmstadt, \\
\hline B. subtilis trpaC2 & $\begin{array}{l}\text { Nonpathogenic, aerobic, endospore-forming, rod-shaped Gram-positive } \\
\text { bacterium, commonly found in soil. }\end{array}$ & $\begin{array}{l}\text { Novagen, } \\
\text { Germany }\end{array}$ & Darmstadt, \\
\hline
\end{tabular}

Expression and secretion of improved cyan fluorescent protein

The coding region of ICFP was fused to the fulllength and truncated forms of ChiSL. Following the transformation of B. subtilis strains with the prepared constructs, the transformants were grown in BSS minimal media in the presence of glucose or chitin. The expression and secretion of ICFP by recombinant $B$. subtilis containing different constructs were confirmed by a change in the color of the medium from brown to green. B. subtilis transformed with pUPChiCFP was grown in three different minimal media, containing the same concentration of glucose along with mannitol, arabinose, or sorbitol; chitin was added to all the media as described earlier. Afterwards, CFP expression and medium color change were checked. It should be mentioned that these sugars lack the ability to inhibit the ChiSL operon through catabolite repression.

\section{SDS-PAGE analysis}

Cells were separated from the growth medium by centrifugation at $5000 \times \mathrm{g}$ at room temperature for 10 min. Medium supernatants were harvested and then concentrated using the addition of TCA (a final concentration of $12 \% \mathrm{w} / \mathrm{v}$ ) on ice for an hour. Equal amounts of proteins were loaded onto the SDS-PAGE gels. Subsequently, cell pellets were resuspended in protoplast buffer $(20 \mathrm{mM}$ potassium phosphate $\mathrm{pH} 7.5$, $15 \mathrm{mM} \mathrm{MgCl}_{2}, 20 \%$ sucrose, and $1 \mathrm{mg}$ lysozyme $/ \mathrm{ml}$ ) and incubated at $37^{\circ} \mathrm{C}$ for $30 \mathrm{~min}$. The resulting protoplasts were dissolved in SDS sample buffer, boiled for $5 \mathrm{~min}$ and analyzed by SDS-PAGE as described previously ${ }^{[21]}$. Next, proteins were transferred from the polyacrylamide gel to a polyvinylidene fluoride membrane (Roche, Germany 21]. CFP signal was then detected by sequential incubation of the membrane with polyclonal anti-GFP antibodies (Molecular Probes, Leiden, the Netherlands) and anti-rabbit horseradish peroxidase-conjugated IgG antibodies (Amersham Biosciences, Little Chalfont, United Kingdom) based on the manufacturers' instructions. GFP shares high amino acid sequence homology with CFP, which makes it possible to use anti-GFP antibodies for the detection of $\mathrm{CFP}^{[23]}$.

\section{Fluorimetric analysis of total extracellular proteins}

Cells were separated from the growth medium by centrifugation at $5000 \times \mathrm{g}$ at room temperature for 10 min. The extracellular proteins in the supernatant were collected, and protein pellets were stored for further analysis ${ }^{[24]}$. Samples were analyzed by a fluorimeter (Perkin-Elmer, Boston, USA) using quartz cuvettes 


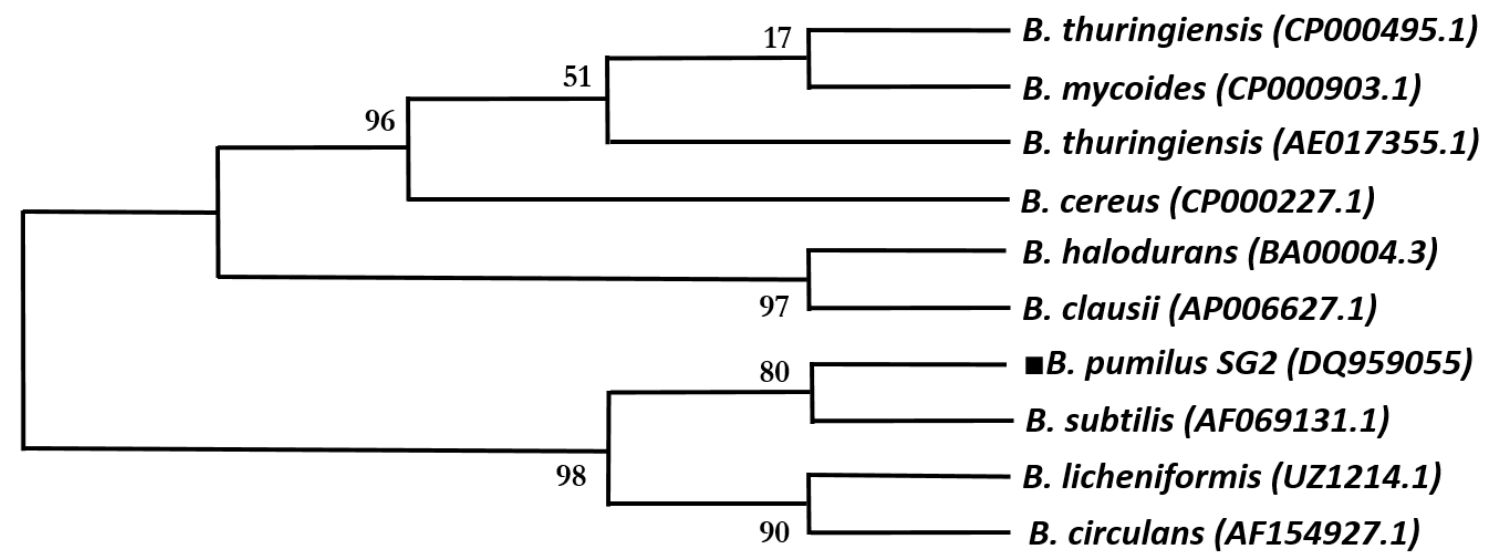

Fig. 1. The phylogenetic tree from the chitinase promoter in the Bacillus species. The ancestral homology of B. pumilus (marked with a black square) is shown through the Bacillus species using original sequence and gene bank accession number of their chitinase promoter.

(Hellma, Müllheim, Germany). The instrument settings to measure CFP fluorescence were as follows: excitation at $300 \mathrm{~nm}$ and emission at $600 \mathrm{~nm}$. During all measurements, the photomultiplier tube voltage was set at $750 \mathrm{~V}$.

\section{RESULTS}

Comparison of the amino acid sequence of catabolite responsive element from different Bacillus species

$\mathrm{CRE}$ is considered as one of the fundamental components in promoters of the B. subtilis genome. It is also involved in the transcription repression of degradative enzymes in the presence of preferred carbon sources in the Bacillus genus. To compare the CRE sequence pattern, the chitinase promoter derived from all Bacillus species was selected and aligned using BioEdit program. Nucleotides above the $90 \%$ identity were chosen to define a pattern. Following to this procedure, a phylogenetic analysis was performed to define the ancestral homology of $B$. pumilus through the Bacillus species using the MEGA5 program (Fig. 1).

Comparison of the consensus pattern of CRE in different Bacillus species showed that B. halodurans and $B$. anthracis, unlike $B$. pumilus SG2, exhibit a rather different pattern. Phylogenetic analysis also demonstrated that $B$. pumilus SG2 shares the most ancestral homology with $B$. subtilis and $B$. Licheniformis (Fig. 2).

\section{B. thuringiensis (CP000495.1) \\ B. halodurans (BA00004.3) \\ T G TAA G A GTATTA T 14 \\ B. cereus (CP000227.1) \\ T C T T T A T GAA TAAA 14 \\ B. mycoides (CP000903.1) \\ T G TAA G A GTATT A T 14 \\ B. clausii (AP006627.1) \\ T G TAA G A GTAT T A T 14 \\ B. anthracis (CP001598.1) \\ C CAAT A T A GA TAAA 14 \\ B. thuringiensis (AE017355.1) \\ TCGCCT T CT T T CAC 14 \\ B. pumilus SG2 (DQ959055) \\ T G TAA GA GTATTAT 13 \\ B. subtilis (AF069131.1) \\ B. licheniformis (UZ1214.1) \\ T G - AA G C GT TT T C T 13 \\ T G - AA G C GTTT T C T 13 \\ B. circulans (AF154927.1) \\ T G - A A G C G T T T T C T 13 \\ G T TAA G C G T T T T C C 14}

Fig. 2. The nucleotide pattern in the cre consensus sequence and the number of nucleotides of the chitinase promoter in the bacillus species. The black boxes show the identity of the nucleotides. 


\author{
pUPChi-ICFP \\ Full length of promoter \\ pUPChi-ICFP 2 \\ Deletion of cre sequence
}
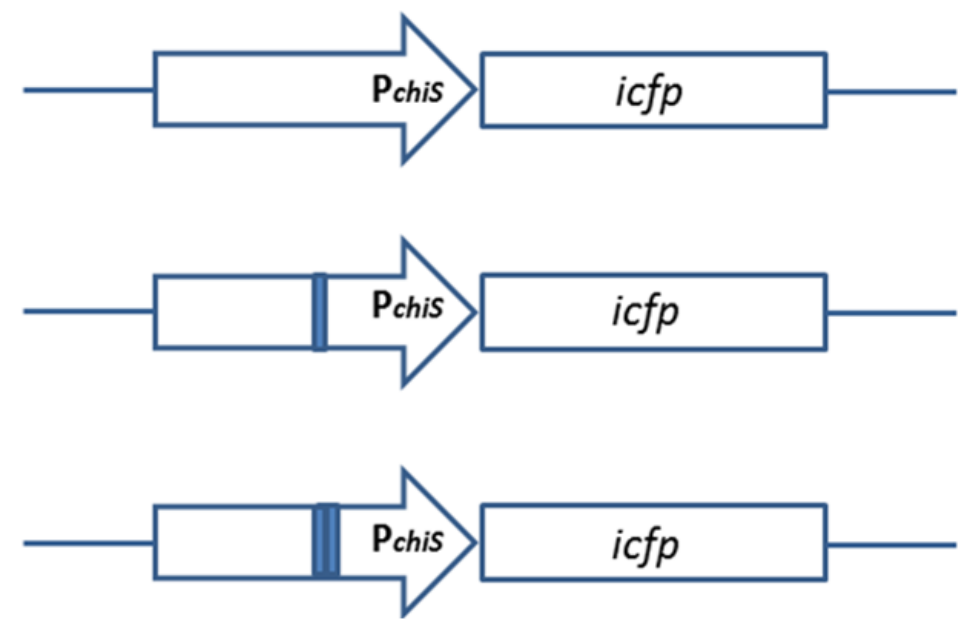

Fig. 3. Schematic presentation of the constructs designed to fuse the coding region of $i c f p$ to the promoter and signal sequence of ChiS.

Construction of different promoter variants for catabolic responsive elements expression

Fusion of the promoter with an unmodified icfp gene in $B$. subtilis has been shown to result in little or no production of fluorescent proteins. For this reason, we attempted to construct improved variants of the promoter expressing ICFP. To this end, the coding sequence of the chitinase promoter from $B$. pumilus SG2 and its variants were fused to the icfp gene as a reporter (Fig. 3), and the expression of the reporter gene was evaluated.

\section{Expression analysis of improved cyan fluorescent protein}

Expression and secretion of ICFP driven by different truncated forms of the ChiSL promoter on minimal media showed that the pUPChi-ICFP3 construct resulted in higher levels of ICFP expression compared to other constructs. This was indicated by color changes in medium (Fig. 4). The SDS-PAGE analysis of culture supernatants obtained from pUPChi-ICFP3 transformants indicated a higher ICFP expression levels in the presence or absence of glucose as a carbon source. Recombinant B. subtilis strains transformed with different ICFP constructs were grown in BSS minimal media in the presence of glucose or chitin, or both. SDS-PAGE analysis followed by western blotting did not detect any ICFP protein in bacterial pellets (data not shown). Medium supernatants were concentrated using TCA, and then equal amounts of proteins were subjected to SDS-PAGE and western blot analysis. The results indicated that a higher level of CFP could be expressed and secreted from B. subtilis containing different versions of the ChiSL promoter grown on the different media. However, the highest expression was observed in
pUPChi-ICFP3 transformants grown in medium containing chitin (Fig. 5).

\section{Fluorimetric assay}

The total fluorescence in extracellular protein extracts was determined using a fluorimeter to quantify the differences in the expression and secretion of CFP. Relative florescent emission of recombinant $B$. subtilis containing pUPChi-CFP, pUPChi-CFP2, and pUPChiCFP3 was determined to be $12.99,29.37$, and 303.8 , respectively. These results demonstrated that the production of ICFP in culture media consisting of chitin or chitin plus glucose is significantly higher in $B$. subtilis containing the UPChi-ICFP3 construct and is

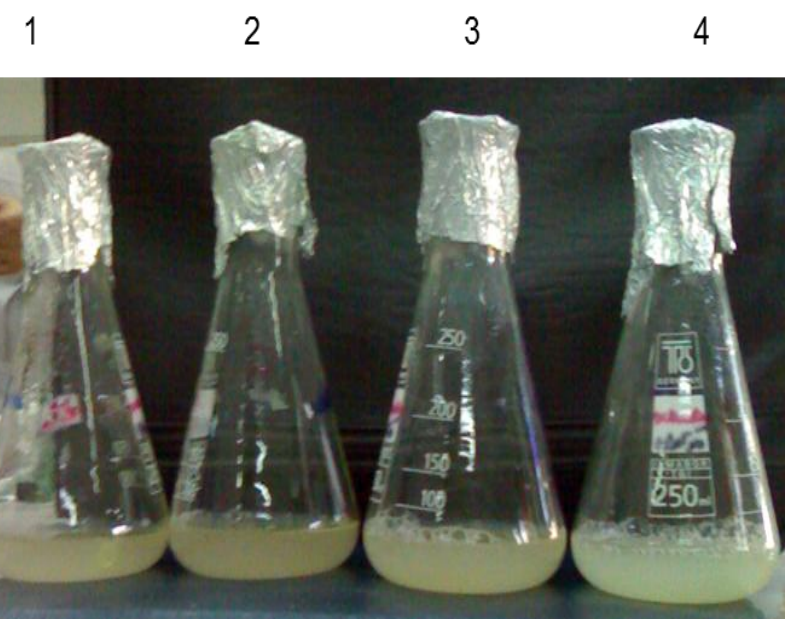

Fig. 4. Expression and secretion of ICFP from different truncated versions of the ChiSL promoter. Transformants were inoculated as follows: 1 through $4, B$. subtilis strains transformed with UPChi-ICFP, UPChi-ICFP2, and UPChiICFP3 that was induced by glucose as a sole carbon source and UPChi-ICFP3 that was induced by glucose and chitin, respectively. 


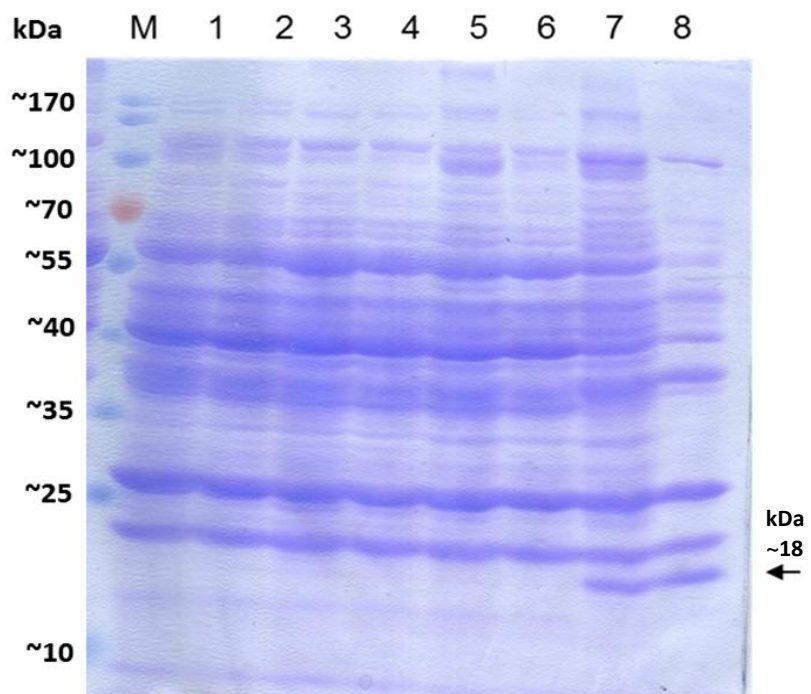

Fig. 5. SDS-PAGE analysis of ICFP expression and secretion from different truncated forms of the ChiSL promoter. Lanes 1 and 2, parent B. subtilis trpC2 168; lanes 3 and 4, UPChi-ICFP; lanes 5 and 6, UPChi-ICFP2; lanes 7 and $8, B$. subtilis transformed with UPChi-ICFP3. Lanes 1, 3, 5, and 7 are medium supernatants containing glucose, while lanes 2, 4, 6 and 8 show medium supernatants containing chitin. Lane 8 also indicates a higher expression level. M, stained protein molecular weight marker.

sufficient to be detected by the fluorometry as compared to the other promoter variants (Figs. 6 and 7).

\section{DISCUSSION}

Promoter is a fragment of the DNA sequence, which drives the transcription of DNA to RNA ${ }^{[24]}$. Promoter strength plays a significant role in genetic engineering and biology. A constitutive promoter with a certain strength for a given RNA can often be reused for other RNAs $^{[25]}$. Both theoretical and experimental methods can be used to evaluate promoter strength; however, there is a need to establish a system capable of assaying and comparing a promoter using promoterreporter fusions.

GFP isolated from the jellyfish, Aequorea victoria, is a versatile reporter used in a wide variety of hosts in in vivo gene expression studies. It has also been shown that the mutagenesis of $g f p$ results in variants with different fluorescent properties ${ }^{[26,27]}$. The CFP and YFP variants of GFP can be detected in cells directly without additives and substrates. This feature introduces them as a suitable marker for in vivo studies of multiple cellular processes within a single cell ${ }^{[28]}$. CFP can be applied as a molecular label or a reporter to visualize the position of a target protein inside living cells and its trafficking, as well as to quantify the protein expression. In addition to its application as a reporter gene, CFP and its derivatives are also used to monitor the introduction and expression of foreign genes in different cells and to evaluate the ability of

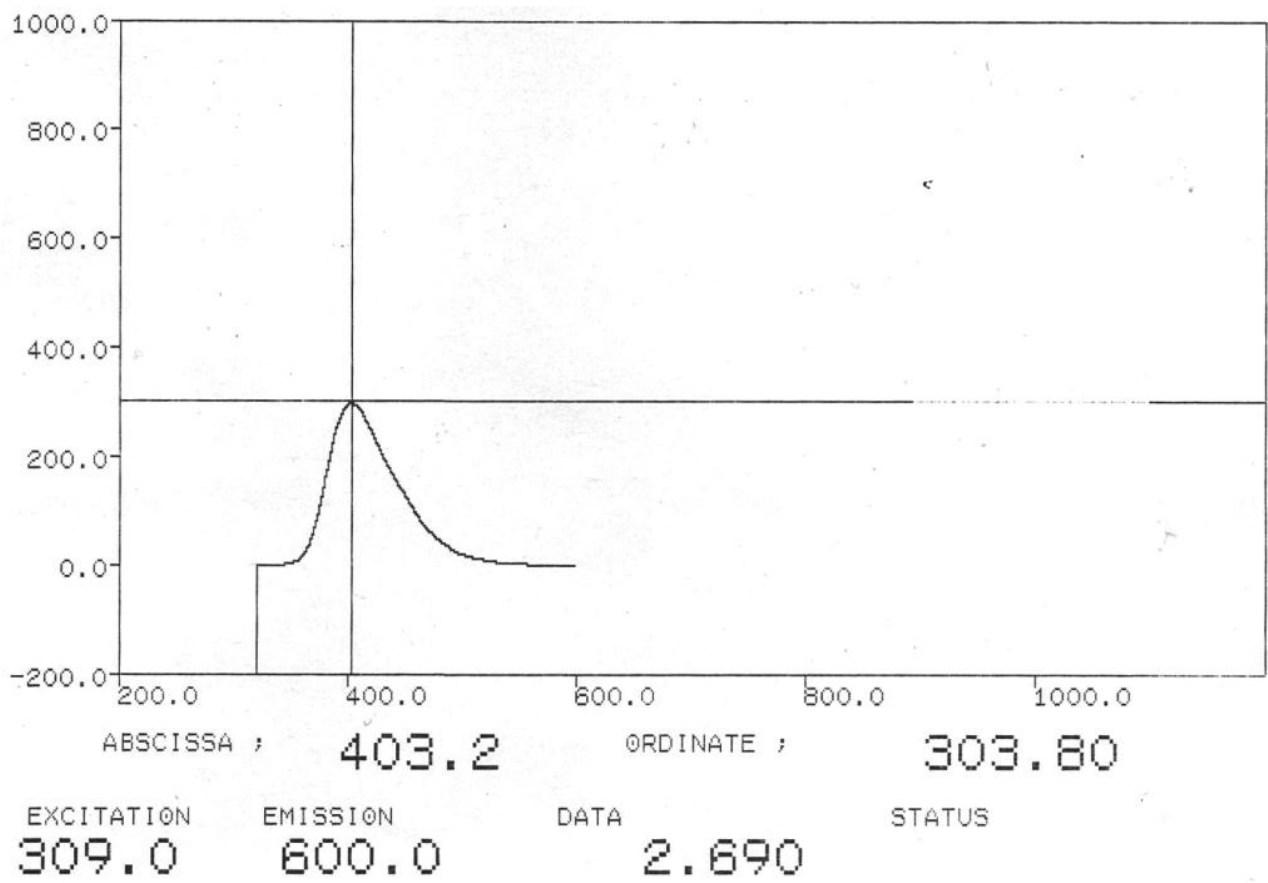

Fig. 6. Florescent emission spectra from culture media of B. subtilis UpChi-CFP3. The horizontal and vertical axes represent the emission wavelength and relative fluorescence emission, respectively. 


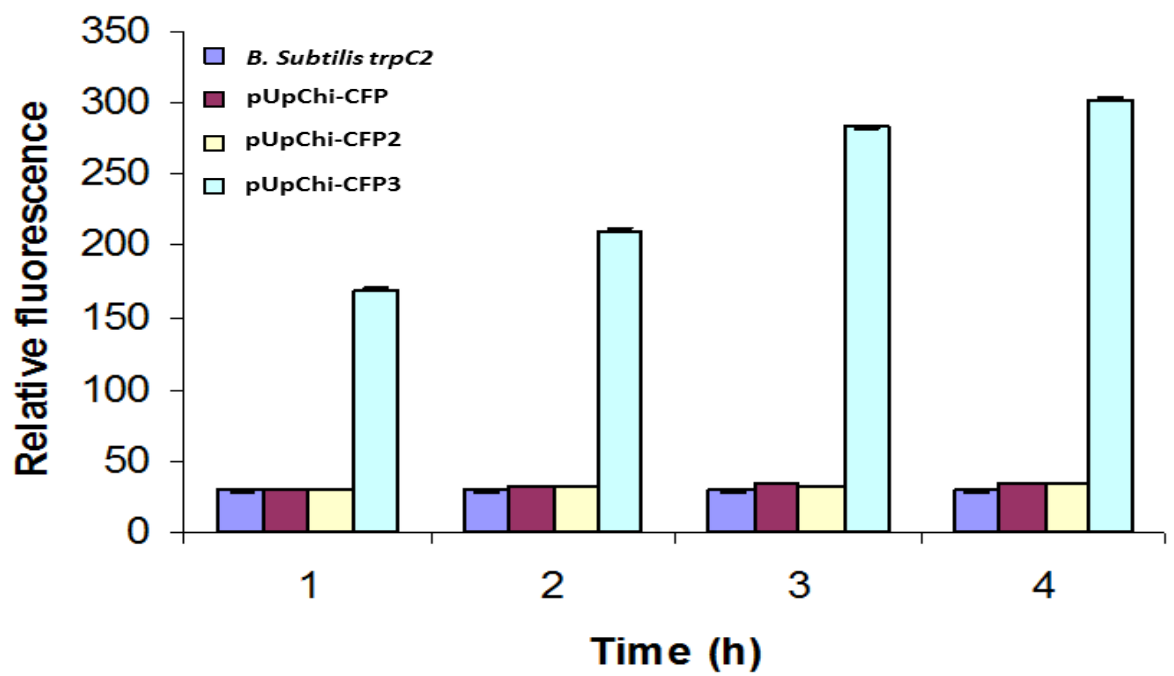

Fig. 7. The fluorimetric assay for detection of relative promoter activity using ICFP, as a reporter protein. The activity of promoters fused to the ICFP reporter genes was detected using a "fluorescence spectrophotometer". For each promoter, fluorescence was measured in quadruplicate, while each promoter was assayed at least in duplicate. Supernatant from the culture medium of B. subtilis $\operatorname{trpC} 2$ was used as a negative control.

transfecting materials to introduce plasmids or proteins into the cell ${ }^{[29]}$.

Since the detection and screening of such transformants are cumbersome and time-consuming, the application of reporters such as luciferase and GFP, which allow transgene expression to be measured, greatly facilitate effective gene transfer technology ${ }^{[29]}$.

GFP has been widely used in eukaryotes, especially in plant systems, for localization experiments and for gene transfer as a screenable marker ${ }^{[30-33]}$. Although used in plant and animal tissues with the same application as GFP, luciferase suffers from some disadvantages, including little toxicity or adverse effects on normal cell metabolism ${ }^{[34]}$. An important advantage of CFP and its optimized version, ICFP, is its suitability for consumption in prokaryotes, especially Bacillus subtilis ${ }^{[34]}$. ICFP is generated by an improvement and modification of CFP ${ }^{[16]}$, making it possible to be used in a variety of gene transfer projects. In addition, this modified CFP, ICFP, has been shown higher fluorescence intensity in Bacillus subtilis. ICFP is widely used in prokaryotes compared to other fluorescent or luminescent markers ${ }^{[34]}$. Since its excitation and emission spectra are distinguishable from other fluorescent proteins, ICFP can be applied for numerous purposes such as co-localization of different proteins in the same cell simultaneously. ICFP is arbitrary for monitoring gene expression and protein displacement both in vivo and in situ ${ }^{[35-38]}$.

The Gram-positive bacterium, B. subtilis, is among the best-studied microbial organisms displaying cellular differentiation. It has been extensively used as a model to study differentiating bacterial cell, secreting large quantities of proteins, and forming highlyresistant spores $^{[39,40]}$. Hence, the availability of easily detectable ICFP in B. subtilis would remarkably facilitate the studies of promoter efficiency analysis in different organisms. The vectors for the production of fluorescent-protein fusions in $B$. subtilis containing the genes $c f p$ and $y f p$ have been studied previously ${ }^{[26]}$. However, these fusions, when expressed in B. subtilis, frequently display no or weak fluorescent signals. Herein, we showed that $i c f p$ is efficiently translated in $B$. subtilis using pUPChi-ICFP3. Furthermore, the chitinase promoter of $B$. pumilus SG2 and its derivative were used to evaluate the expression and secretion of ICFP. The full-length form was able to express ICFP at a very low level, which was undetectable by SDSPAGE. However, the truncated version containing deletion in the CRE box and its upstream sequence in the pUPChi-CFP3 strain showed more effective expression and secretion of ICFP. Our present results revealed that inserting this truncated form of Chi promoter upstream of the ICFP, as a reporter gene, in $B$. subtilis led to an approximately tenfold increase in ICFP expression.

\section{ACKNOWLEDGEMENTS}

This work was carried out in and supported financially by the National Institute of Genetic Engineering and Biotechnology (NIGEB) of Iran (Tehran, Iran).

CONFLICT OF INTEREST. None declared. 


\section{REFERENCES}

1. Al-Dosari MS, Gao X. Nonviral gene delivery: principle, limitations, and recent progress. The AAPS journal 2009; 11(4): 671-681.

2. Hackett PB, Largaespada DA, Cooper LJ. A transposon and transposase system for human application. Molecular therapy 2010; 18(4): 674-683.

3. Herzog RW, Cao O, Srivastava A. Two decades of clinical gene therapy--success is finally mounting. Discovery medicine 2010; 9(45): 105-11.

4. Li Z, Jayasankar S, Gray DJ. Expression of a bifunctional green fluorescent protein (GFP) fusion marker under the control of three constitutive promoters and enhanced derivatives in transgenic grape (Vitis vinifera). Plant science 2001; 160(5):877-87.

5. Samac DA, Tesfaye M, Dornbusch M, Saruul P, Temple SJ. A comparison of constitutive promoters for expression of transgenes in alfalfa (Medicago sativa). Transgenic research 2004; 13(4): 349-61.

6. Ducrest AL, Amacker M, Lingner J, Nabholz M. Detection of promoter activity by flow cytometric analysis of GFP reporter expression. Nucleic acids research 2002; 30(14): e65.

7. Ahmadian G, Degrassi G, Venturi V, Zeigler DR, Soudi M, Zanguinejad P. Bacillus pumilus SG2 isolated from saline conditions produces and secretes two chitinases. Journal of applied microbiology 2007; 103(4): 10811089.

8. Vahed M, Motalebi E, Rigi G, Akbari Noghabi K, Soudi MR, Sadeghi M, Ahmadian G. Improving the chitinolytic activity of Bacillus pumilus SG2 by random mutagenesis. Journal of microbiology and biotechnology 2013; 23(11): 1519-28.

9. Heravi KM, Shali A, Naghibzadeh N, Ahmadian G. Characterization of cis-acting elements residing in the chitinase promoter of Bacillus pumilus SG2. World journal of microbiology and biotechnology 2014; 30(5): 1491-1499.

10. Morabbi Heravi K, Rigi G, Rezaei Arjomand M, Rostami A, Ahmadian G. An alternative bacterial expression system using Bacillu pumilus SG2 chitinase promoter. Iranian journal of biotechnology 2015; 13(4): $17-24$.

11. Chalfie M, Tu Y, Euskirchen G, Ward WW, Prasher DC. Green fluorescent protein as a marker for gene expression. Science 1994; 263(5148): 802-805.

12. Dubnau D. The regulation of genetic competence in Bacillus subtilis. Molecular microbiology 1991; 5(1): 11-8.

13. Elowitz MB, Levine AJ, Siggia ED, Swain PS. Stochastic gene expression in a single cell. Science 2002; 297(5584): 1183-1186.

14. Errington J. Bacillus subtilis sporulation: regulation of gene expression and control of morphogenesis. Microbiological reviews 1993; 57(1): 1-33.

15. Losick R, Stragier P. Crisscross regulation of cell-typespecific gene expression during development in Bacillus subtilis. Nature 1992; 355(6361): 601-604.
16. Veening JW, Smits WK, Hamoen LW, Jongbloed JD, Kuipers OP. Visualization of differential gene expression by improved cyan fluorescent protein and yellow fluorescent protein production in Bacillus subtilis. Applied and environmental microbiology 2004; 70(11): 6809-6815.

17. Apweiler $\mathrm{R}$, Bairoch $\mathrm{A}$, $\mathrm{Wu} \mathrm{CH}$, Barker WC, Boeckmann B, Ferro S, Gasteiger E, Huang H, Lopez R, Magrane M, Martin MJ, Natale DA, O'Donovan C, Redaschi N, Yeh LS. UniProt: the universal protein knowledgebase. Nucleic acids research 2004; 32(suppl 1): D115-D119.

18. Hall TA. BioEdit: a user-friendly biological sequence alignment editor and analysis program for Windows 95/98/NT. Nucleic acids symposium 1999; 41: 95-98.

19. Thompson JD, Higgins DG, Gibson TJ. CLUSTAL W: improving the sensitivity of progressive multiple sequence alignment through sequence weighting, position-specific gap penalties and weight matrix choice. Nucleic acids research 1994; 22(22): 46734680.

20. Tamura K, Peterson D, Peterson N, Stecher G, Nei M, Kumar S. MEGA5: molecular evolutionary genetics analysis using maximum likelihood, evolutionary distance, and maximum parsimony methods. Molecular biology and evolution 2011; 28(10): 2731-2739.

21. Sambrook JF, Russell DW. Molecular Cloning: A Laboratory Manual. $3^{\text {rd }}$ ed., New York: Cold Spring Harbor Laboratory Press; 2012.

22. Leskela S, Kontinen VP, Sarvas M. Molecular analysis of an operon in Crisscross regulation of cell-typespecific gene expression during development in Bacillus subtilis encoding a novel $\mathrm{ABC}$ transporter with a role in exoprotein production, sporulation and competence. Microbiology 1996; 142(Pt 1): 71-77.

23. Kaltwasser M, Wiegert T, Schumann W. Construction and application of epitope- and green fluorescent protein-tagging integration vectors for Crisscross regulation of cell-type-specific gene expression during development in Bacillu subtilis. Applied and environmental microbiology 2002; 68(5): 2624-2628.

24. Hidde de Jong, Johannes Geiselmann. Fluorescent Reporter Genes and the Analysis of Bacterial Regulatory Networks. Springer 2015; 7699: 27-50.

25. Li J, Zhang Y. Relationship between promoter sequence and its strength in gene expression. The European physical journal E 2014; 37(9): 44.

26. Lau YL, Shamilah H, Fong MY. Characterisation of a truncated Toxoplasma gondii surface antigen 2 (SAG2) secreted by the methylotrophic yeast Pichia pastoris. Tropical biomedicine 2006; 23(2): 186-193.

27. Heim R, Tsien RY. Engineering green fluorescent protein for improved brightness, longer wavelengths and fluorescence resonance energy transfer. Current biology 1996; 6(2): 178-182.

28. Matz MV, Fradkov AF, Labas YA, Savitsky AP, Zaraisky AG, Markelov ML, Lukyanov SA. Fluorescent proteins from nonbioluminescent Anthozoa species. Nature biotechnology 1999; 17(10): 969-973. 
29. Birch RG. Plant transformation: problems and strategies for practical application. Annual review of plant physiology and plant molecular biology 1997; 48: 297 326.

30. Köhler RH, Cao J, Zipfel WR, Webb WW, Hanson MR. Exchange of protein molecules through connections between higher plant plastids. Science 1997; 276(5321): 2039-2042.

31. Padgett HS, Epel BL, Kahn TW, Heinlein M, Watanabe Y, Beachy RN. Distribution of tobamovirus movement in infected cells and implications for cell-to-cell spread of infection. The plant journal 1996; 10(6): 1079-1088.

32. Sheen J, Hwang S, Niwa Y, Kobayashi H, Galbraith DW. Green fluorescent protein as a new vital marker in plant cells. The plant journal 1995; 8(5): 777-784.

33. Köhler RH, Zipfel WR, Webb WW, Hanson MR. The green fluorescent protein as a marker to visualize plant mitochondria in vivo. The plant journal 1997; 11(3): 613-621.

34. Alam J, Cook JL. Reporter genes: applications to the study of mammalian gene transcription. Analytical biochemistry 1990; 188(2): 245-254.
35. Chalfie M, Tu Y, Euskirchen G, Ward WW, Prasher DC. Green fluorescent protein as a marker for gene expression. Science 1994; 263(5148): 802-805.

36. Prasher DC, Eckenrode VK, Ward WW, Prendergast FG, Cormier MJ. Primary structure of the Aequorea victoria green-fluorescent protein. Gene 1992; 111(2): 229-233.

37. Inouye S, Tsuji FI. Evidence for redox forms of the Aequorea green fluorescent protein. FEBS Letters 1994; 351(2): 211-214.

38. Wang S, Hazelrigg $\mathrm{T}$. Implications for bcd mRNA localization from spatial distribution of exu protein in Drosophila oogenesis. Nature 1994; 369(6479): 400403.

39. Errington, J. Bacillus subtilis sporulation: regulation of gene expression and control of morphogenesis. Microbiological reviews 1993; 57: 1-33.

40. Losick R, Stragier p. Crisscross regulation of cell-typespecific gene expression during development in Crisscross regulation of cell-type-specific gene expression during development in Bacillus subtilis. Nature 1992; 355: 601-604. 